\title{
Fluid sparing and norepinephrine use in a rat model of resuscitated haemorrhagic shock: end-organ impact
}

Sophie Dunberry-Poissant ${ }^{1}$, Kim Gilbert ${ }^{2}$, Caroline Bouchard ${ }^{2}$, Frédérique Baril ${ }^{3}$, Anne-Marie Cardinal ${ }^{3}$, Sydnée L'Ecuyer ${ }^{3}$, Mathieu Hylands ${ }^{4}$, François Lamontagne ${ }^{5,6}$, Guy Rousseau ${ }^{2,7}$ and Emmanuel Charbonney ${ }^{1,2^{*}}$

\footnotetext{
* Correspondence: emmanuel. charbonney@umontreal.ca

'Département de Médecine, Université de Montréal, C.P. 6128 Succursale Centre-ville, Montréal, QC H3C 3J7, Canada

${ }^{2}$ Centre de Recherche Hôpital du Sacré-Cœur de Montréal (HSCM), 5400 boul. Gouin Ouest, Montréal, QC H4J 1C5, Canada

Full list of author information is available at the end of the article
}

\begin{abstract}
Background: Haemostasis and correction of hypovolemia are the pillars of early haemorrhage shock (HS) management. Vasopressors, which are not recommended as first-line therapy, are an alternative to aggressive fluid resuscitation, but data informing the risks and benefits of vasopressor therapy as fluid-sparing strategy is lacking. We aimed to study its impact on end organs, in the setting of a haemodynamic response to the initial volume resuscitation.
\end{abstract}

Methods: Following controlled HS (60 min) induced by blood withdrawal, under anaesthesia and ventilation, male Wistar rats ( $N=10$ per group) were randomly assigned to (1) sham, (2) HS with fluid resuscitation only [FR] and (3) HS with fluid resuscitation to restore haemodynamic (MAP: mean arterial pressure) then norepinephrine [FR+NE]. After a reperfusion time (60 min) during which MAP was maintained with fluid or norepinephrine, equipment was removed and animals were observed for $24 \mathrm{~h}$ $(N=5)$ or $72 \mathrm{~h}(N=5)$ before euthanasia. Besides haemodynamic parameters, physiological markers (creatinine, lactate, $\mathrm{pH}, \mathrm{PaO}_{2}$ ) and one potential contributor to vasoplegia (xanthine oxidase activity) were measured. Apoptosis induction (caspase 3), tissue neutrophil infiltration (MPO: myeloperoxidase) and illustrative protein markers were measured in the lung (Claudin-4), kidney (KIM-1) and brain amygdala (Iba1).

Results: No difference was present in MAP levels during HS or reperfusion between the two resuscitation strategies. FR required significantly more fluid than FR+NE ( $183 \%$ vs $106 \%$ of bleed-out volume; $p=0.003$ ), when plasma lactate increased similarly. Xanthine oxidase was equally activated in both HS groups. After FR+NE, creatinine peaked higher but was similar in all groups at later time points. FR+NE enhanced MPO in the lung, when Claudin-4 increased significantly after FR. In the brain amygdala, FR provoked more caspase 3 activity, MPO and microglial activation (Iba1 expression).

Conclusion: Organ resuscitation after controlled HS can be assured with lesser fluid administration followed by vasopressors administration, without signs of dysoxia or worse evolution. Limiting fluid administration could benefit the brain and seems not to have a negative impact on the lung or kidney.

Keywords: Haemorrhage shock, Vasopressors, Norepinephrine, Fluid sparing, End-organ impact 


\section{Background}

Polytrauma is a major cause of mortality worldwide [1], and haemorrhagic shock (HS) is the main pathway to early mortality after trauma [2].

According to current guidelines, initial management of HS consists of rapid haemostasis with concurrent repletion of blood volume with warmed crystalloid and blood products. Fluid resuscitation restores circulating volume in order to compensate for decreased end-organ perfusion. However, large volumes of intravenous fluids can lead to dilutional coagulopathy, hypothermia and acidosis [3, 4], as well as tissue oedema and prolonged mechanical ventilation [5].

The debate surrounding the optimal resuscitation strategy remains unresolved, both in the pre-hospital setting and during late resuscitation [5, 6]. Vasopressors, which are not currently recommended for HS, constitute a potential fluid-sparing strategy [7]. They are commonly used when polytrauma is associated with traumatic brain injury, presumably to avoid low cerebral perfusion pressures $[8,9]$. However, existing clinical data remains inconclusive and their net effects remain uncertain [10].

Vasopressors' ultimate impact on tissue perfusion is unclear, as any benefits of higher arterial pressure may be offset by increased microvascular resistance. Microcirculatory derangements and vasoplegia commonly persist despite adequate fluid resuscitation in the setting of haemorrhagic shock [11]. Organ failure can then result, partly through the release of nitric oxide and peroxynitrites $[12,13]$; interestingly, a large number of preclinical haemorrhagic shock models have studied the role of xanthine oxidase activation as a culprit [14, 15].

When used alone or in high doses in animal HS models, vasopressors are associated with increased mortality [16]; combined with fluid resuscitation, survival is improved compared to fluid resuscitation alone [16-18]. In another study, a restrictive fluid strategy combined with vasopressor therapy leads to better lung compliance and reduced pulmonary oedema but higher serum lactate concentrations [19].

The aim of our study was to compare the end-organ impact (lung, kidney and brain) of a mean arterial pressure (MAP)-directed fluid resuscitation with or without norepinephrine (NE), in a rat model of controlled HS. We hypothesized that the addition of NE would lower fluid requirements, which could have a differential biologic impact on different end organs. Besides haemodynamic, fluid-related and physiological variables, we also measured plasma levels of a vasoplegia contributor (xanthine oxidase), tissue apoptosis induction program (caspase 3) and tissue neutrophil infiltration (myeloperoxidase). Specific protein's expression was chosen from the literature to illustrate phenomenon that could respond to differential resuscitation in the organs studied: for the kidney, the kidney injury molecule-1(KIM-1) was chosen as marker of the proximal tubular epithelium ischemia [20]; for the lung, Claudin-4 (a junctional protein) was chosen for its induced expression after lung injury and its role in fluid clearance [21]; and for the brain, the ionized calcium binding adaptor molecule 1 (Iba1) was chosen as an ischemia-sensitive protein, specifically expressed in microglia and reflecting inflammatory activation [22].

\section{Methods}

\section{Experimental design}

Thirty-three male Wistar rats weighing 400 to 450 g (aged 12 to 15 weeks; Charles River Canada, St-Constant, QC, Canada) were housed individually, under constant 
conditions (temperature $21-22{ }^{\circ} \mathrm{C}$ and humidity $40-50 \%$ ), including a 12-h dark-light cycle beginning at $8 \mathrm{AM}$. Chow pellets and tap water were available ad libitum throughout the study. An acclimatization period of 3 days after delivery by the supplier was imposed before the rats were allocated to the experimental groups. We chose to use norepinephrine (NE), since it is widely available and used by clinicians [23]. The animals $(N=10)$ were randomly assigned to one of the three experimental groups: (1) sham, (2) HS with fluid resuscitation only [FR] and (3) HS with both fluid resuscitation and NE $[\mathrm{FR}+\mathrm{NE}]$. The number of animals per groups was based on the survival rate reported with similar doses of $\mathrm{NE}$ in a rat model [16]. On the morning of the experiments, two rats were prepared and anesthetized, then allocated in parallel to two of the experimental groups.

\section{Surgical procedure and haemorrhagic shock model (Fig 1)}

Anaesthesia was induced by intraperitoneal ketamine/xylazine injection (60 and $10 \mathrm{mg} / \mathrm{kg}$, respectively). Subsequently, the rats were intubated, ventilated under volume control parameters $(6 \mathrm{ml} / \mathrm{kg})$ and received oxygen (FiO2 100\%). Anaesthesia was maintained with isoflurane (1-2\%). After lidocaine administration $(5 \mathrm{mg} / \mathrm{kg} \mathrm{SC})$, catheters were placed in the femoral vein (for blood subtraction, plasma sampling and fluid administration) and in the femoral artery (for monitoring of arterial pressure) under sterile conditions. Catheters were fixed with silk sutures. Oxygen saturation (pulse oximetry) and temperature (with a rectal probe) were monitored. Blood was drawn until the mean arterial pressure (MAP) fell to $30 \mathrm{mmHg}$ [24], and the subtracted volume was recorded. This degree of hypotension was maintained for 60 min to reflect the clinical effects of trauma-induced hypovolemia and hypoperfusion. The sham group was equipped with catheters and observed for the same duration but blood was not removed.

In both groups, resuscitation was initiated with shed blood (stored at $37{ }^{\circ} \mathrm{C}$ with citrate) mixed with Ringer's lactate (1:1). In the FR group, boluses of 1-2 ml were constantly administered, in order to maintain a MAP 55-60 mmHg. In the FR+NE group, rats were initially resuscitated with a bolus totalizing $40 \%$ of the blood volume initially withdrawn; this percentage had been evaluated in pilot experiments and determined as the minimal volume to reach the target MAP. Thereafter, an infusion of NE $(0.1 \mathrm{mg} \backslash \mathrm{ml})$ was started at $2 \mathrm{mcg} / 100 \mathrm{~g} / \mathrm{h}$ and titrated to target a MAP 55-60 mmHg for $45 \mathrm{~min}$. Volume was then administered to wean $\mathrm{NE}$ and reach a MAP of $60 \mathrm{mmHg}$ at

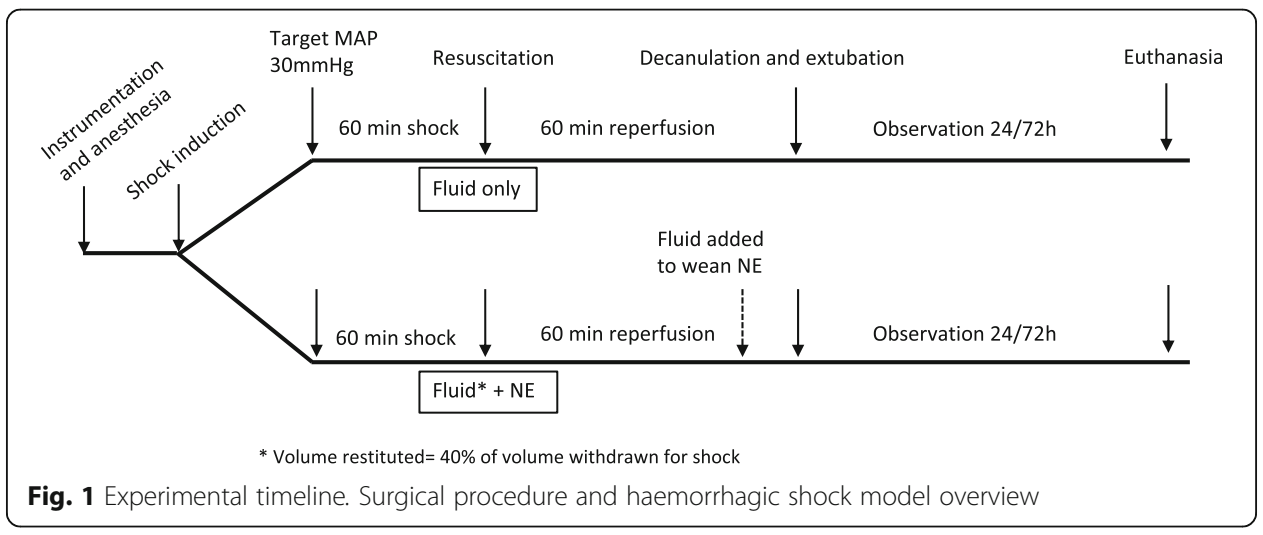


anaesthesia interruption. After $60 \mathrm{~min}$ of reperfusion, catheters were removed, vessels ligated, and a subcutaneous analgesic injection $(0.05 \mathrm{mg} / \mathrm{kg}$ buprenorphine) was administered. The rats were then extubated and allowed to eat and drink (water consumption was monitored) before their euthanasia at two pre-specified time points $(24 \mathrm{~h}$ or $72 \mathrm{~h}$; $N=5$ per time point). Another buprenorphine injection was administered the next day. Three rats died in the first hour following reperfusion $(<10 \%$ of the total cohort), one in the FR+NE group and two in the FR group. Animals were added until five animals completed the experiment ( 24 and $72 \mathrm{~h}$ ) in each group (FR, FR+NE). All animals that survived the initial resuscitation period survived until the final euthanasia.

As a measure of general recovering state and given the difference in fluid administration between the groups, weight loss till euthanasia and water intake during the first $24 \mathrm{~h}$ after HS were measured.

The animals were euthanized by decapitation under deep anaesthesia with intraperitoneal ketamine/xylazine injection (60 and $10 \mathrm{mg} / \mathrm{kg}$, respectively). After euthanasia, organs (kidney, lung and brain) and plasma were retrieved, frozen in liquid nitrogen and stored at $-80^{\circ} \mathrm{C}$ until analysis.

\section{Laboratory assays}

Blood $(0.5 \mathrm{ml})$ was collected at baseline, at the end of the reperfusion period (preceding decanulation) and at the time of euthanasia ( $24 \mathrm{~h}, 72 \mathrm{~h}$ ). In all groups, creatinine level and arterial blood gases $\left(\mathrm{pH}, \mathrm{PaO}_{2}\right.$, lactate) were assessed at baseline, at reperfusion and at euthanasia (results pooled for $24 \mathrm{~h}$ and $72 \mathrm{~h}$ ), using a VetScan i-StatC (Abaxis Inc., California, USA). Plasma xanthine oxidase activity was measured at reperfusion and at euthanasia, according to the protocol provided by the manufacturer (Xanthine Oxidase Fluorometric Assay Kit, Cayman Chemicals number 10010895).

Caspase 3 activity was measured according to a previously described protocol [25]. Tissues were homogenized by sonication in a lysis buffer and incubated for $30 \mathrm{~min}$ on ice. After three freeze/thaw cycles, tissue homogenates were centrifuged at $4{ }^{\circ} \mathrm{C}$ for $10 \mathrm{~min}$. Enzymatic reactions were undertaken in a buffer with $25 \mathrm{mg}$ of protein (confirmed by the Bradford method) and $40 \mu \mathrm{M}$ of fluorescent substrates (Ac-DEV$\mathrm{D}-\mathrm{AMC}$ and Ac-IETD-AMC for caspase 3). The reactions were assessed after a 3-h incubation in the dark at $37{ }^{\circ} \mathrm{C}$ and stopped with the addition of $0.4 \mathrm{M} \mathrm{NaOH}$ and $0.4 \mathrm{M}$ glycine buffer. Fluorescence was quantified by spectrofluorometry (Photon Technology International, Lawrenceville, NJ, USA) at an excitation wavelength of $365 \mathrm{~nm}$ and an emission wavelength of $465 \mathrm{~nm}$ for caspase 3 activities.

Neutrophil accumulation in the tissue was estimated by myeloperoxidase assay as described previously [26]. Organ's tissues were first weighed, added to a hexadecytrimethylamonium bromide (HTAB) buffer $(0.5 \% \mathrm{HTAB}+50 \mathrm{mM}$ potassium phosphate, $\mathrm{pH}$ 6.0) and pulverized by sonication. The lysates were subjected to three freeze/thaw cycles and centrifuged at 21,000 $\mathrm{g}$ for $15 \mathrm{~min}$. To quantify myeloperoxidase activity, $0.1 \mathrm{ml}$ of supernatant was added to $2.9 \mathrm{ml}$ of $50 \mathrm{mM}$ sodium phosphate ( $\mathrm{pH}$ 6.0) with $0.167 \mathrm{mg} / \mathrm{ml}$ of o-dianisidine hydrochloride and $0.0005 \%$ hydrogen peroxide. Absorbance of the orange product was then measured by spectrophotometer every $10 \mathrm{~s}$ at $460 \mathrm{~nm}$ for $2 \mathrm{~min}$. Difference was generated between the maximum and minimum divided by 2 to estimate neutrophil accumulation. 


\section{Western blotting}

The increase in expression of selected proteins known to respond to systemic injury was measured in the end organ as a read-out of the HS-related ischemic damage. Briefly, tissues were homogenized by sonication in a lysis buffer (1\% Triton X-100, $0.32 \mathrm{~mol} / \mathrm{l}$ sucrose, $10 \mathrm{mmol} / \mathrm{l}$ Tris (pH 8.0), $5 \mathrm{mmol} / \mathrm{l} \mathrm{EDTA,} 2 \mathrm{mmol} / \mathrm{l}$ DTT, $1 \mathrm{mmol} / \mathrm{l}$ PMSF, $10 \mathrm{mg} / \mathrm{ml}$ Leupeptin, $10 \mathrm{mg} / \mathrm{ml}$ Pepstatin A, $10 \mathrm{mg} / \mathrm{ml}$ Aprotinin). The tissue homogenates were incubated for $30 \mathrm{~min}$ at $4{ }^{\circ} \mathrm{C}$ and centrifuged at $10,000 \mathrm{~g}$ for $15 \mathrm{~min}$. Protein concentrations of the supernatant were quantified by the Lowry method. Aliquots of $100 \mathrm{mcg}$ protein were loaded in polyacrylamide gels (10-15\%) and migrated at $150 \mathrm{~V}$ for $75 \mathrm{~min}$ in a mini-gel apparatus (BioRad Laboratories, Hercules, CA, USA). Proteins were transferred to nitrocellulose membranes with a Trans-Blot semi-dry transfer cell (BioRad Laboratories). Using SNAP i.d. 2.0 system (Millipore, Etobicoke, Ontario, Canada), non-specific sites were blocked for $20 \mathrm{~min}$, incubated in Odyssey blocking buffer (Li-CoR, Lincoln, Nebraska, USA) (1:1 with PBS). After PBS washing, membranes were incubated for 15 min with primary antibody 1:1000 (Novus biologicals NBP2-46655 pAb anti-TIM-1/KIM-1/HAVCR anti-rabbit: KIM-1), (rabbit pAb Claudin-4 abcam ab53156), (Rabbit Iba1 pAb Wako 019-19,741) and actin (anti-actin rabbit Ab sigma A2066). After washing, the membranes were incubated for $10 \mathrm{~min}$ with secondary antibody 1: 15,000 (anti-rabbit IRDye 800CW Li-Cor). The membranes were scanned with Odyssey LI-COR $\mathrm{Clx}$, and band intensities were analysed with image studio. The same membranes were placed in stripping buffer $(0.1 \mathrm{~mol} / \mathrm{l}$ glycine, $1 \% \mathrm{SDS}, \mathrm{pH} 2.0,1 \mathrm{~h}$ at room temperature $)$ and reused with the same technique for ratio determination KIM-1/actin, Claudin-4/actin and Iba1/actin ratio.

\section{Statistical analysis}

The data are reported as means $( \pm$ SEM). Statistical analyses were performed by SPSS 19. Data were compared with analysis of variance (ANOVA), followed by Bonferroni correction for univariate multiple comparisons, when parametric. If variances were heterogeneous, Brown-Forsythe correction was followed by Games-Howell comparisons when applicable. Comparison of within groups variable changes were done using Kruskal-Wallis test. All $p$ values compare either the HS groups to the sham group or the HS groups to one another. $p<0.05$ was considered significant.

\section{Results}

\section{Resuscitation, haemodynamic and monitoring parameters}

At baseline, MAP and heart rate (HR) were comparable in all groups. Resuscitation and haemodynamic parameters during HS are displayed in Table 1. The bleed-out volumes of the two HS groups (FR vs FR+NE) were equivalent (15.6 \pm 1.2 vs $17.1 \pm 1.2 \mathrm{ml}$; $p=0.38$ ). During HS, the lowest MAP reached was the same ( $27 \pm 1$ vs $26.5 \pm 0.5 \mathrm{mmHg}$; $p=0.66)$, as well as the time spent under MAP of $30 \mathrm{mmHg}(11.1 \pm 1.6$ vs $10.5 \pm 1.1 \mathrm{~min}$; $p=0.73)$. The $\mathrm{FR}+\mathrm{NE}$ group was resuscitated with the pre-established limited volume $(11 \pm 1 \mathrm{ml})$, with a MAP $\geq 55 \mathrm{mmHg}$ in all animals. Thereafter, when MAP fell below, NE was infused (total average dose of $9.2 \mathrm{mcg}$ ) until the end of the reperfusion period (60 min); additional fluid was then necessary $(9.3 \pm 1.7 \mathrm{ml})$, in order to wean NE, before extubation. The FR group received a total amount of $27.5 \pm 1.5 \mathrm{ml}$ of fluid for 
Table 1 Resuscitation, haemodynamic and monitoring parameters

\begin{tabular}{|c|c|c|c|}
\hline & $\begin{array}{l}\text { Sham } \\
N=10\end{array}$ & $\begin{array}{l}\mathrm{HS}: \mathrm{FR}+\mathrm{NE} \\
N=10\end{array}$ & $\begin{array}{l}\text { HS: FR } \\
N=10\end{array}$ \\
\hline Bleed-out volume, $\mathrm{ml}$ & 0 & $17.1 \pm 1.2$ & $15.6 \pm 1.2$ \\
\hline Resuscitation volume (\%) & 0 & $106 \pm 11^{* *}$ & $183 \pm 17$ \\
\hline Cumulative NE, mcg & 0 & $9.2 \pm 0.8$ & 0 \\
\hline \multicolumn{4}{|l|}{ MAP, mmHg } \\
\hline Baseline & $65 \pm 3$ & $66 \pm 2$ & $65 \pm 2$ \\
\hline Shock & $63 \pm 2$ & $29 \pm 1^{*}$ & $29 \pm 1^{*}$ \\
\hline Reperfusion & $67 \pm 5$ & $59 \pm 3$ & $54 \pm 2$ \\
\hline \multicolumn{4}{|l|}{$\mathrm{HR}$, bpm } \\
\hline Baseline & $267 \pm 13$ & $263 \pm 11$ & $265 \pm 18$ \\
\hline Shock & $266 \pm 14$ & $247 \pm 11$ & $248 \pm 15$ \\
\hline Reperfusion & $273 \pm 15$ & $321 \pm 11$ & $394 \pm 14$ \\
\hline \multicolumn{4}{|l|}{ Temperature, ${ }^{\circ} \mathrm{C}$} \\
\hline Baseline & $35 \pm 0.9$ & $36 \pm 0.2$ & $34 \pm 0.6$ \\
\hline Shock & $35 \pm 0.8$ & $36 \pm 0.2$ & $34 \pm 0.6$ \\
\hline Reperfusion & $35 \pm 0.6$ & $37 \pm 0.2$ & $35 \pm 0.4$ \\
\hline \multicolumn{4}{|l|}{ Saturation, \% } \\
\hline Baseline & $98 \pm 0.5$ & $98 \pm 0.5$ & $96 \pm 0.7$ \\
\hline Shock & $98 \pm 0.5$ & $98 \pm 0.5$ & $96 \pm 0.9$ \\
\hline Reperfusion & $97 \pm 0.5$ & $98 \pm 0.5$ & $97 \pm 0.5$ \\
\hline
\end{tabular}

resuscitation and MAP maintenance. During the reperfusion period till extubation, the FR vs $\mathrm{FR}+\mathrm{NE}$ lowest MAP reached was not different ( $54 \pm 2$ vs $51 \pm 2 \mathrm{mmHg} ; p=0.24$ ), as well as the time spent under MAP of $55 \mathrm{mmHg}(7.8 \pm 1.6$ vs $8.0 \pm 1.1 \mathrm{~min} ; p=0.92)$.

At the time of extubation and decanulation, the group of rats resuscitated with fluids only (FR) had required more fluids than animals resuscitated with FR+NE (183\% vs 106\% of bleed-out volume; $p=0.003$ ). During reperfusion, both HS groups were comparable and had lower MAP and higher HR than the sham group. No differences were noted in terms of saturation or temperature between groups (Table 1).

\section{Organ function and dysoxia}

HS induced a significant rise in lactate at the end of reperfusion compared to baseline in the HS groups $(p=0.006)$, but serum lactate concentrations were comparable in both HS groups (Table 2). No difference was noted in terms of $\mathrm{PaO}_{2}$ or $\mathrm{pH}$. Creatinine level increased significantly within HS groups $(p=0.037)$. At the end of reperfusion, creatinine was significantly increased compared to shams in the FR+NE group (absolute level and delta; $p<0.05$ ). Delta creatinine was non-significantly higher in the group of FR+NE compared to FR after reperfusion (Delta A). When animals were euthanized, creatinine level (Delta B) in the FR vs FR+NE groups was not different, and similarly, no differences were noted between $24 \mathrm{~h}$ and $72 \mathrm{~h}$ creatinine levels in each arm. Animals lost more weight during the first $24 \mathrm{~h}$ and recovered partially at $72 \mathrm{~h}$, 
Table 2 Physiological parameters measured

\begin{tabular}{|c|c|c|c|c|}
\hline & $\begin{array}{l}\text { Sham } \\
N=10\end{array}$ & $\begin{array}{l}H S: F R+N E \\
N=10\end{array}$ & $\begin{array}{l}\mathrm{HS}: \mathrm{FR} \\
N=10\end{array}$ & $\begin{array}{l}P \\
F R \text { vs } F+N E\end{array}$ \\
\hline \multicolumn{5}{|l|}{ Lactates, mmol/l } \\
\hline Baseline & $0.56 \pm 0.11$ & $0.66 \pm 0.12$ & $0.47 \pm 0.07$ & NS \\
\hline Reperfusion" ${ }^{\#}$ & $0.77 \pm 0.20$ & $1.50 \pm 0.22$ & $1.16 \pm 0.27$ & NS \\
\hline Delta lactate & $0.21 \pm 0.18$ & $0.76 \pm 0.34^{\S}$ & $0.69 \pm 0.29^{\S}$ & NS \\
\hline \multicolumn{5}{|l|}{$\mathrm{pH}$} \\
\hline Baseline & $7.38 \pm 0.03$ & $7.42 \pm 0.03$ & $7.48 \pm 0.04$ & NS \\
\hline Reperfusion\# & $7.37 \pm 0.01$ & $7.37 \pm 0.03$ & $7.41 \pm 0.03$ & NS \\
\hline \multicolumn{5}{|l|}{$\mathrm{PaO} 2, \mathrm{mmHg}$} \\
\hline Baseline & $328 \pm 31$ & $336 \pm 30$ & $309 \pm 49$ & NS \\
\hline Reperfusion" & $334 \pm 28$ & $339 \pm 24$ & $301 \pm 18$ & NS \\
\hline \multicolumn{5}{|l|}{ Creatinine, mg/dl } \\
\hline Baseline & $0.32 \pm 0.05$ & $0.33 \pm 0.03$ & $0.29 \pm 0.05$ & NS \\
\hline Reperfusion"\# & $0.34 \pm 0.07$ & $0.71 \pm 0.11^{\S}$ & $0.53 \pm 0.10$ & NS \\
\hline Euthanasia & $0.26 \pm 0.08$ & $0.32 \pm 0.06$ & $0.26 \pm 0.03$ & NS \\
\hline Delta creatinine $A^{*}, \mathrm{mg} / \mathrm{dl}$ & $0 \pm 0.04$ & $0.30 \pm 0.08^{\S}$ & $0.20 \pm 0.05$ & NS \\
\hline Delta creatinine $\mathrm{B}^{* *}, \mathrm{mg} / \mathrm{dl}$ & $0 \pm 0.06$ & $0 \pm 0.06$ & $0 \pm 0.06$ & NS \\
\hline
\end{tabular}

Values are reported as Mean \pm SEM. "Measured at the end of the reperfusion period

*Delta creatinine A (end of reperfusion-baseline); ${ }^{* *}$ Delta creatinine B (at euthanasia-baseline). ${ }^{\S} p<0.05$ vs sham

with no difference between groups. Fluid intake was equal within the first $24 \mathrm{~h}$ for sham and HS groups (Table 3).

\section{Plasmatic xanthine oxidase activity}

Xanthine oxidase activity increased after HS, at the end of reperfusion compared to sham $(p<0.05)$; no difference was noted between the resuscitation strategies and xanthine oxidase activity in HS groups decreased to values similar to sham at $24 \mathrm{~h}$ and 72 h (Fig. 2).

\section{Makers of apoptosis: caspase 3}

Caspase 3 activity was measured in the three organs (kidney, Fig 3a; lung, Fig. 3b; brain, Fig. 3c). In the kidney and in the lung, caspase 3 activity increased at $24 \mathrm{~h}$ and $72 \mathrm{~h}$ following HS compared to sham $(p<0.05)$. No statistically significant difference was present, despite a trend towards higher expression at $72 \mathrm{~h}$ in both organs for the $\mathrm{FR}+\mathrm{NE}$ group. In the brain-amygdala, caspase 3 activity increased at

Table 3 Animal's follow-up

\begin{tabular}{lccc}
\hline & Sham & FR+NE & FR \\
\hline Weight change, g & & $-22 \pm 4$ \\
$24 \mathrm{~h}$ & $-24 \pm 4$ & $-19 \pm 5$ & $-11 \pm 4$ \\
$72 \mathrm{~h}$ & $-10 \pm 10$ & $-11 \pm 2$ & \\
Water intake, $\mathrm{ml}$ & $76 \pm 10$ & $77 \pm 12$ & $80 \pm 14$ \\
$24 \mathrm{~h}$ & & \\
\hline \multicolumn{2}{l}{ Values are reported as mean \pm SEM }
\end{tabular}

Values are reported as mean \pm SEM 


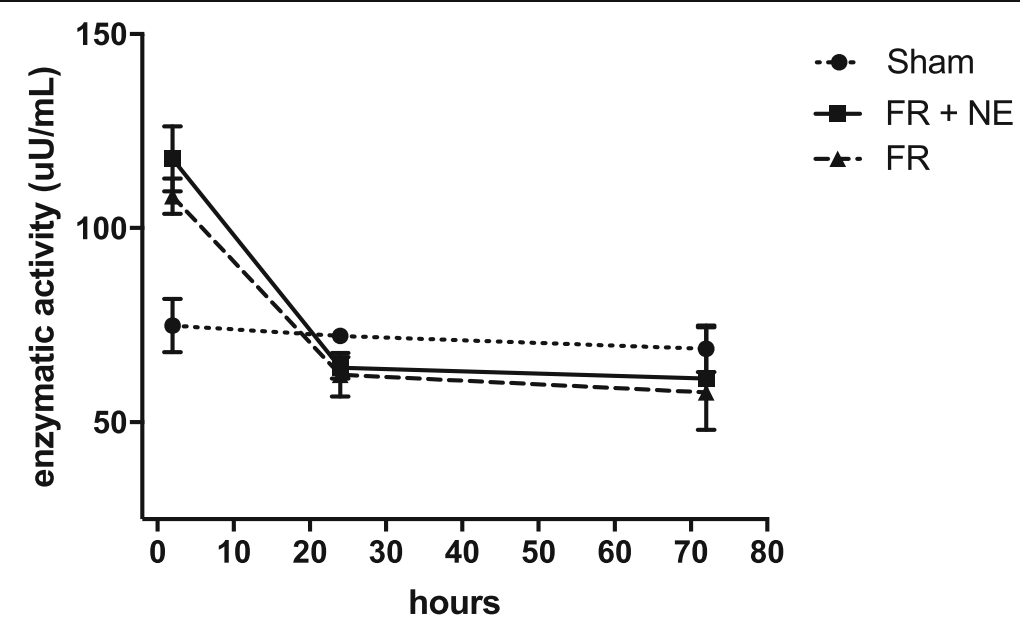

Fig. 2 Plasmatic xanthine oxidase. Xanthine oxidase concentration assessed by ELISA after 2, 24 and $72 \mathrm{~h}$ of reperfusion and expressed in $\mathrm{uU} / \mathrm{ml}$. N $=4-5 /$ group at each time point, and asterisk indicates a significant difference between HS vs sham group, $(p<0.05)$

$24 \mathrm{~h}$ following both resuscitated HS compared to sham $(p<0.05)$ but was significantly higher in the FR compared to FR+NE at $72 \mathrm{~h}(p=0.002)$.

\section{Neutrophil's infiltration (MPO in tissues)}

Myeloperoxidase activity (MPO), representing a surrogate of neutrophils influx, was measured (kidney, Fig 4a; lung, Fig. 4b; brain, Fig. 4c). MPO in the kidney was significantly higher in both HS groups at $24 \mathrm{~h}$ of resuscitation (vs sham; $p<0.05$ ) but disappeared at $72 \mathrm{~h}$. In the lung, however, HS led to increased MPO which was significantly higher in the $\mathrm{FR}+\mathrm{NE}$ group compared to FR at $24 \mathrm{~h}(p=0.001)$ and $72 \mathrm{~h}(p=0.007)$. In the brain amygdala, the HS shock led to increased MPO only after FR at $24 \mathrm{~h}$ (vs sham; $p<0.05)$; at $72 \mathrm{~h}, \mathrm{MPO}$ activity was increased after both HS, but significantly higher after FR compared to FR+NE $(p<0.01)$.

\section{Protein markers of organ injury after ischemia}

Post HS, the expression of selected proteins was measured in the end organs. In the kidney (Fig. 5a), KIM-1 was increased as expected after HS $(p<0.05)$, but no difference between the resuscitation strategies was visible at both time points, even if it was not significantly higher at $24 \mathrm{~h}$ with NE. In the lung (Fig. 5b), Claudin-4 expression was strongly induced after HS in the FR group compared to shams at $24 \mathrm{~h}(p=0.001)$, when it decreased slightly with FR+NE. The difference between FR and FR+NE was very significant $(p<0.001)$. Its expression was however reduced at $72 \mathrm{~h}$ in both resuscitation strategies, compared to sham $(p<0.05)$. To note that after HS, the lung wet/dry ratio was increased (1.8-fold), without differences between the resuscitation groups (data not shown). In the brain amygdala, no induction of Iba1 was noted after HS (Fig. 5c). After $72 \mathrm{~h}$, Iba1 expression was significantly enhanced in the amygdala after HS only in the FR group vs sham $(p=0.035)$. 


\section{A}

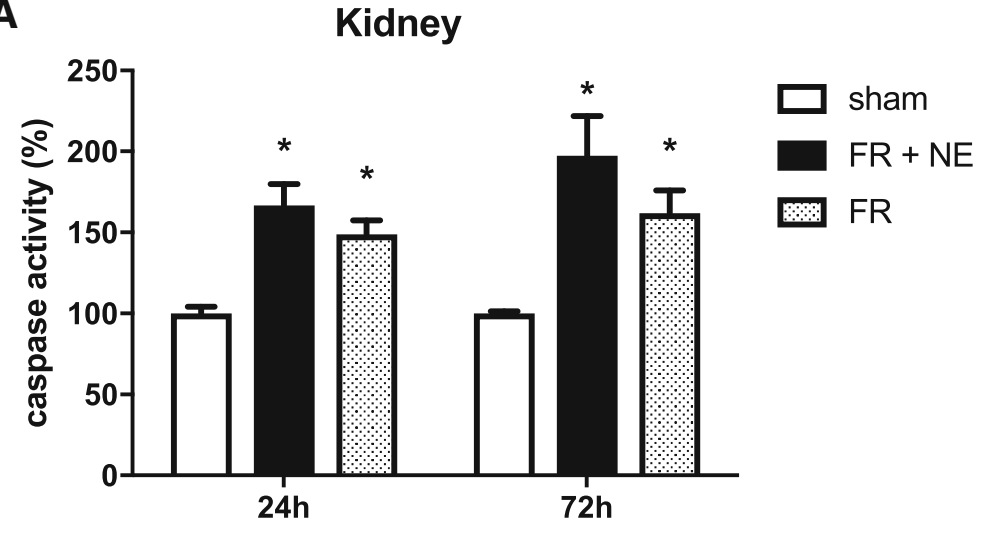

B

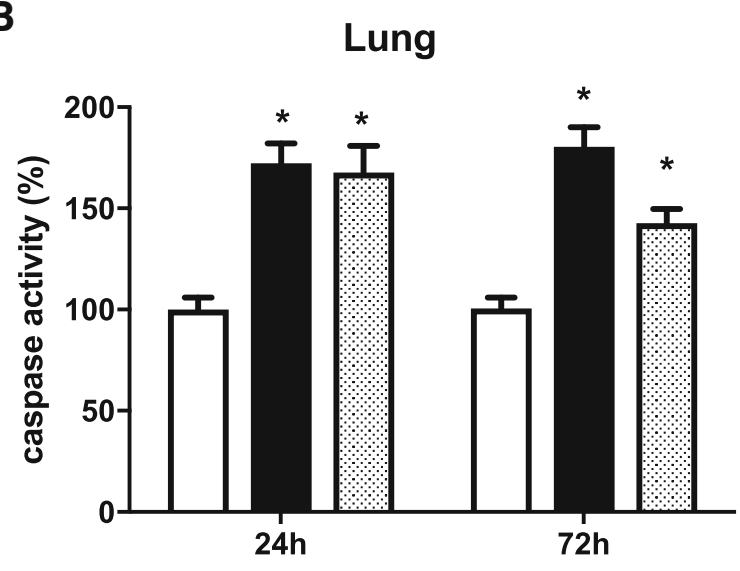

C

Brain (amygdal)

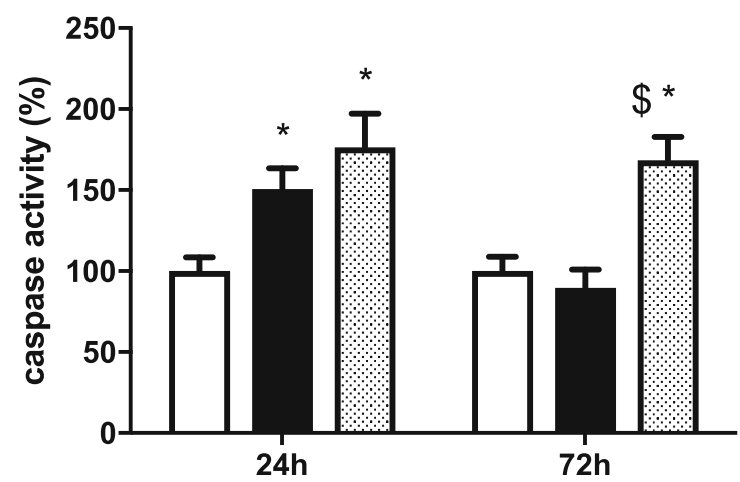

Fig. 3 Caspase 3 activity in organs. Caspase 3 activity kidney (a), lung (b) and brain amygdala (c), expressed as the percentage of the mean activity observed in the sham group, set to $100 \%$ and assessed by in vitro spectrofluorescence after $24 \mathrm{~h}$ and $72 \mathrm{~h}$ of reperfusion. $N=5 /$ group and asterisk indicates significant difference between both HS groups vs sham group, except for FR+NE group in brain amygdala at $72 \mathrm{~h}(p<0.05)$; dollar sign indicates significant difference between FR vs FR+NE in brain amygdala at $72 \mathrm{~h}(p=0.002)$

\section{Discussion}

Our animal model represents a resuscitation strategy involving the use of a vasopressor once bleeding is controlled and partial volemic resuscitation is achieved. Our results are consistent with previous reports that demonstrate the fluid-sparing effect of vasopressors [7]; indeed, the use of vasopressors allowed us to achieve resuscitation with a 


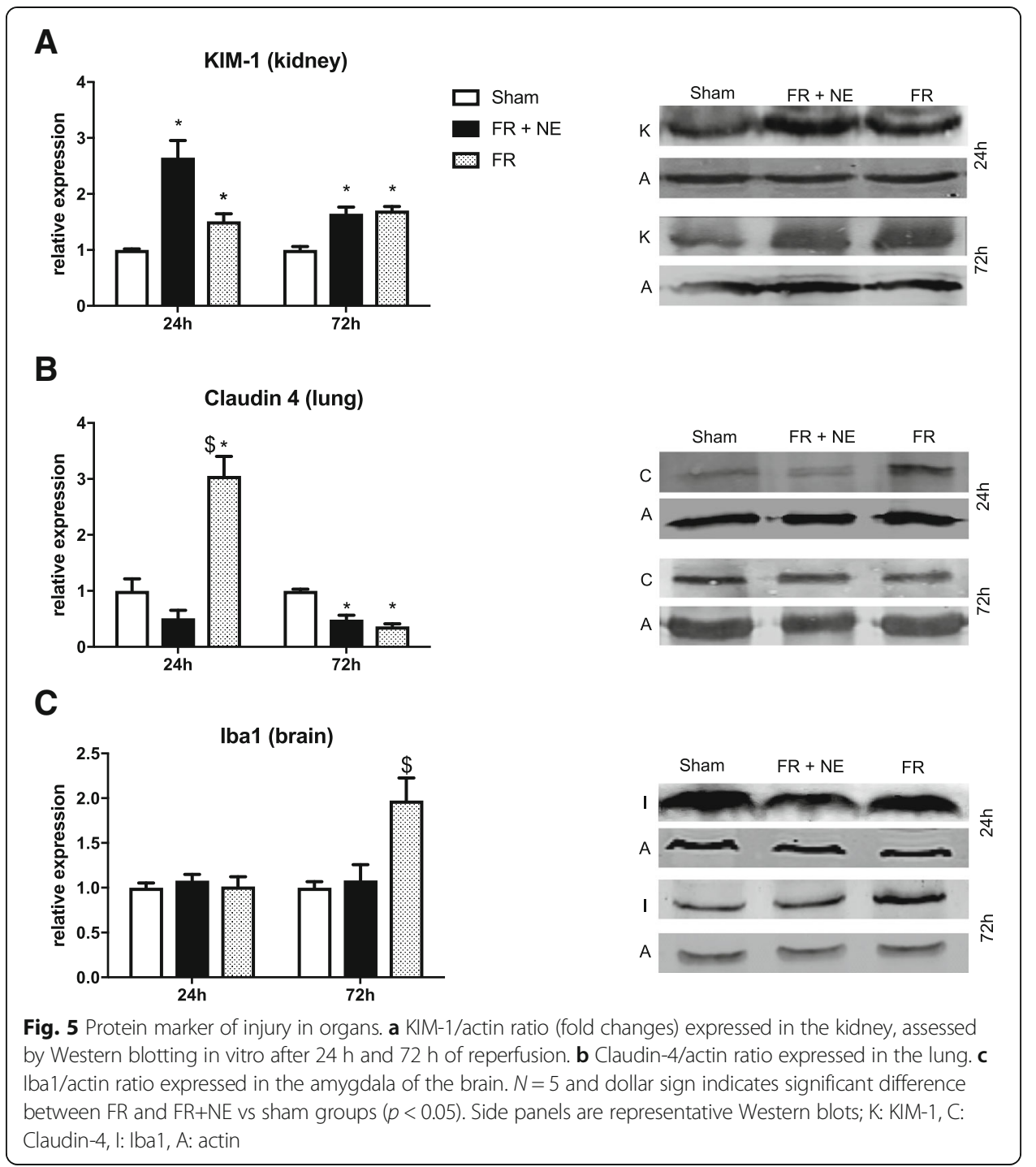

volume equal to the haemorrhage amount. This is likely due to venous volume recruitment, increased heart contractility and maintenance of end-organ blood flow [27]. Already in the 1970s, Drees et al. had shown venoconstriction to be able to mobilize blood volume [28]. More recently, animal studies as well as human have demonstrated the effect of norepinephrine on venous return, then improving cardiac output [29-31].

The excess amount of fluid necessary to maintain adequate blood pressure without vasopressors, explained by the probable ischemia-reperfusion induced vasoplegia, confirmed the findings of Dalibon et al. [32]. This vasoplegia hypothesis is also supported by the initial restoration of MAP with smaller volume of blood reinfusion, followed by a need for more fluids to maintain the same MAP target [32]. We could not measure vascular resistance in our model, but we measured xanthine oxidase activity, as one marker of HS-induced vasoplegia [33]. Our observation of increased xanthine oxidase activity after HS was in accordance with what had been described in the past [15]. Neither the higher fluid volumes nor the use of vasopressors modified its expression during or after the resuscitation phase. 


\section{A}

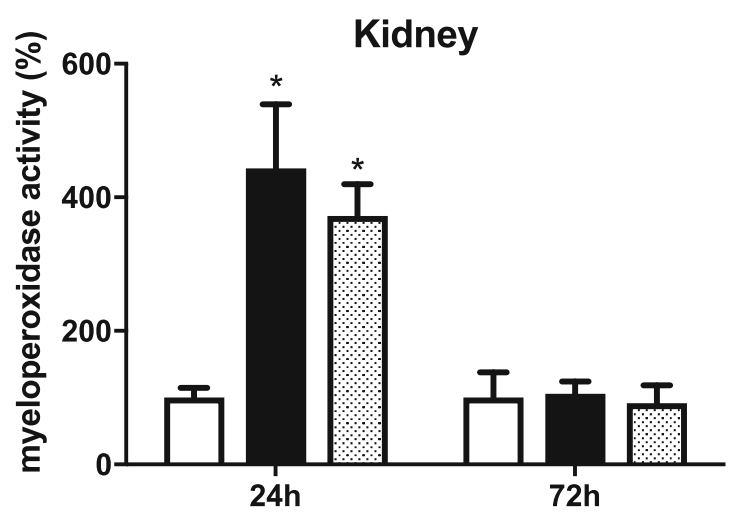

B

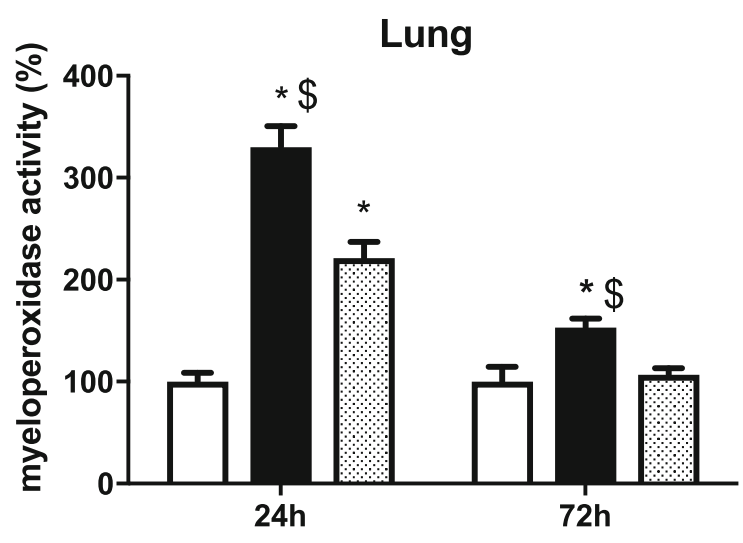

C Brain (amygdal)

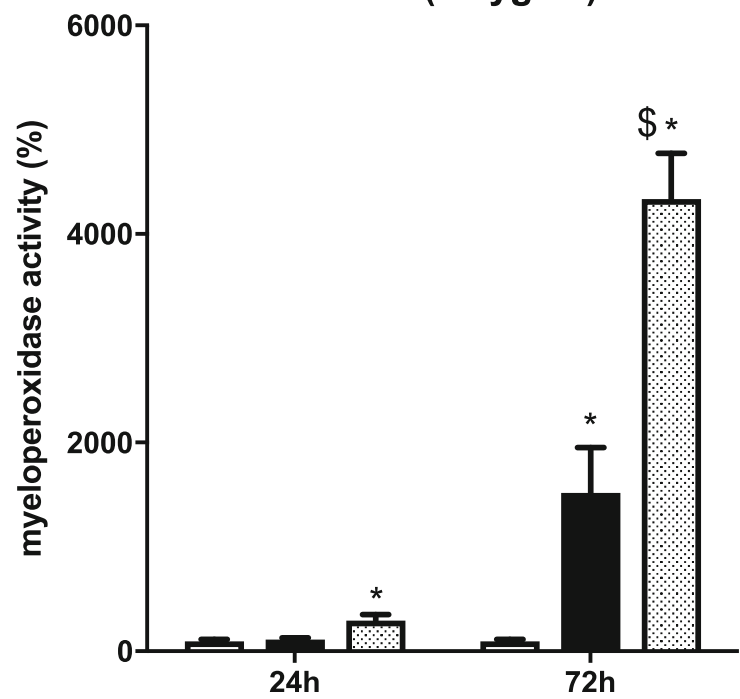

Fig. 4 Myeloperoxidase activity in organs. Myeloperoxidase activity in the kidney (a), lung (b) and brain amygdala (c), expressed as percentage of the mean of the sham group set as 100\%, assessed by enzymatic reactions after $24 \mathrm{~h}$ and $72 \mathrm{~h}$ of reperfusion. $N=5 / g r o u p$ and asterisk indicates significant difference between HS vs sham group and dollar sign indicates FR vs FR+NE $(p<0.05)$ 
Vasopressor therapy did not modify lactate levels, suggesting that restrictive fluid therapy did not increase anaerobic metabolism; it is then unlikely that excessive vasoconstriction was present, in contrast to other model of progressive bleeding [34]. In addition, we found no difference in saturation, $\mathrm{PaO}_{2}, \mathrm{pH}$ and temperature.

In the kidney, despite the peak of creatinine during reperfusion and a slightly higher KIM-1 with vasopressors and less fluid administered, the evolution was identical between the two resuscitation strategies. After HS and reperfusion, the increase of creatinine was in the magnitude (2-fold) of similar models [24] and the higher peak may be explained by the pre-renal effect of fluid sparing in the group with vasopressors. The fact that the ischemic-sensitive expression of kidney injury molecule-1(KIM-1) [20] was temporarily enhanced, even if not significantly, cannot exclude a vasopressor-induced vasoconstriction in a state of relative hypovolemia [35]. The return to baseline levels in each group (Delta creatinine B) was observed in our comparative model, but does not necessarily demonstrate an equivalent recovery of kidney function, given the limitation of sole creatinine measurement [36].

In the lung, the use of vasopressors seemed to enhance neutrophil infiltration until $72 \mathrm{~h}$. It is known that the catecholamine released during HS can modulate the systemic inflammation; particularly, the alpha-adrenergic effect can activate lung neutrophils [37]. On the other end, the chosen lung protein marker Claudin-4 expression was increased at $24 \mathrm{~h}$ following HS, after fluid resuscitation only. It is particularly interesting since this junction protein can be highly expressed after lung injury and is involved in the maintenance of alveolar barrier function and fluid clearance [21, 38]; at the later time point, its expression was decreased in both groups, likely secondary to inflammation [39]. Regarding the differential expression at $24 \mathrm{~h}$, we can hypothesize that the fluid volume overload due to resuscitation after ischemia-reperfusion might have triggered a temporary compensatory reaction to enhance fluid clearance; in the group exposed to vasopressor, the observed inhibition might have happened secondary to TNF- $\alpha$ in the context of enhanced inflammation [39]. Further elucidation of the mechanistic reason is needed.

The major differential effect of the two resuscitation strategies, as well as the more congruent findings, was in the brain. To note that in our model, the amygdala was used as a sensitive zone of the brain but does not represent the consequences that might occur in other parts. Fluid resuscitation alone did provoke more caspase 3 activation, more MPO and more microglia activation (Iba1) particularly at the later time point. No difference in brain perfusion pressure was suspected, given the similar MAP during shock or resuscitation. One explanation could be that the excess of fluid administered impacts on blood-brain barrier and contributes to worsen the ischemic amygdala [40]. Early works had already measured the increase of brain damage if resuscitated with fluid after brain ischemia [41]; it has to be verified with more sophisticated measure of permeability. Nevertheless, it supports the beneficial effect of vasopressors use as a fluid sparing, beyond the sole purpose of maintaining MAP for perfusion pressure.

Some authors reported that global ischemia-reperfusion does not increase MPO expression in rat brain [42], when others did [43]. We found a significant increase of MPO after HS at the later time point, particularly if resuscitated with fluid only. The magnitude of our global ischemia and the timing might have allowed the deterioration of blood-brain barrier integrity to develop [44]. These findings parallel the 
improvement of brain oxygenation and decreased intra-cranial pressure observed after resuscitation using vasopressors instead of fluids only [45].

We acknowledge some limitations of our work. First, our focused approach is limited by the three chosen organs. In addition, our model differs from previous reports, since the frame of our research question targets the post-emergency management period, where the bleeding and its sources have been controlled. It is in contrast with the existing experimental literature, where vasopressors are administered simultaneously during fluid resuscitation [16, 45]. Finally, the biomarkers chosen are only illustrative of specific phenomenon, without relevance for common mechanisms or measurable effect on organ's function. The selection of them is a matter of debate, and our choices were made among numerous existing biomarker. Additional microcirculatory, as well as more functional assessment of organ integrity/ischemia, could have enhanced the clinical relevance of our findings.

Nevertheless, our observations contribute to support the resuscitation approach using vasopressors as fluid sparing once the haemorrhage is controlled, particularly for the brain. It is also reassuring regarding the impact on the kidney, particularly given the known recognized association between fluid overload and acute kidney injury. As for the lung, the limitation of fluids administration is already an accepted principle among clinicians, particularly after lung transplantation and ARDS.

\section{Conclusion}

Our data show that the organ perfusion can be assured with lesser fluid administration followed by vasopressors administration in order to resuscitate HS, once controlled. No sign of dysoxia or worst evolution is provoked with this approach. Even more, it suggests that limiting the fluid administration could benefit the brain and seems not to have a negative impact on the lung or kidney.

\section{Abbreviations}

FR+NE: Fluid resuscitation and norepinephrine; FR: Fluid resuscitation; HR: Heart rate; HS: Haemorrhage shock; Iba1: Ionized calcium binding adaptor molecule 1; KIM-1: Kidney injury molecule-1; MAP: Mean arterial pressure; MPO: Myeloperoxidase activity

Acknowledgements

Not applicable

Funding

The research was funded by the Centre de Recherche Hôpital du Sacré-Cœur de Montréal.

Availability of data and materials

Please contact author for data requests.

Authors' contributions

$\mathrm{SDP}, \mathrm{KG}, \mathrm{GR}$ and EC contributed to the design of the animal study, the acquisition of data, the analysis and interpretation of the results. They drafted the manuscript and revised the final version. CB, FB, AMC and SL'E contributed to the acquisition of data, the analysis and interpretation of the results. They actively participated to the drafting of the manuscript, the critical revision of it and the approval of the final version. $\mathrm{MH}$ and FL contributed to the ideas and clinically driven concepts of the design, the analysis and interpretation of the results. They actively participated in the critical revision of the manuscript and the approval of the final version. All authors read and approved the final manuscript.

Ethics approval

The experimental protocols were approved by the institutional animal research ethical board of the Centre de Recherche de l'Hôpital du Sacré-Cœur de Montréal (\#REB-CHAE03), and the animals were handled in compliance with regulations of the local animal care committee and with guidelines of the Canadian Council on Animal Care. 
Competing interests

The authors declare that they have no competing interests.

\title{
Publisher's Note
}

Springer Nature remains neutral with regard to jurisdictional claims in published maps and institutional affiliations.

\begin{abstract}
Author details
'Département de Médecine, Université de Montréal, C.P. 6128 Succursale Centre-ville, Montréal, QC H3C 3J7, Canada. ${ }^{2}$ Centre de Recherche Hôpital du Sacré-Cœur de Montréal (HSCM), 5400 boul. Gouin Ouest, Montréal, QC H4J 1C5, Canada. ${ }^{3}$ Université de Montréal, 2900 Edouard Montpetit Blvd, Montréal, QC H3T 1J4, Canada. ${ }^{4}$ Département de chirurgie, Université de Sherbrooke, 3001-12e avenue Nord, Sherbrooke, QC J1H 5N4, Canada. ${ }^{5}$ Centre de recherche du CHU de Sherbrooke, 3001- 12e avenue Nord, Sherbrooke, QC J1H 5N4, Canada. 'Department of Medicine, Université de Sherbrooke, 3001-12e avenue Nord, Sherbrooke, QC J1H 5N4, Canada. ${ }^{7}$ Département de pharmacologie et physiologie, Université de Montréal, C.P. 6128 Succursale Centre-ville, Montréal, QC H3C 3J7, Canada.
\end{abstract}

Received: 8 May 2018 Accepted: 29 October 2018

Published online: 12 November 2018

\section{References}

1. Haagsma JA, Graetz N, Bolliger I, Naghavi M, Higashi H, Mullany EC, Abera SF, Abraham JP, Adofo K, Alsharif U, Ameh EA, Ammar W, Antonio CAT, Barrero LH, Bekele T, Bose D, Brazinova A, Catalá-López F, Dandona L, Dandona R, Dargan PI, De Leo D, Degenhardt L, Derrett S, Dharmaratne SD, Driscoll TR, Duan L, Petrovich Ermakov S, Farzadfar F, Feigin VL, Franklin RC, Gabbe B, Gosselin RA, Hafezi-Nejad N, Hamadeh RR, Hijar M, Hu G, Jayaraman SP, Jiang G, Khader YS, Khan EA, Krishnaswami S, Kulkarni C, Lecky FE, Leung R, Lunevicius R, Lyons RA, Majdan M, Mason-Jones AJ, Matzopoulos R, Meaney PA, Mekonnen W, Miller TR, Mock CN, Norman RE, Orozco R, Polinder S, Pourmalek F, Rahimi-Movaghar V, Refaat A, Rojas-Rueda D, Roy N, Schwebel DC, Shaheen A, Shahraz S, Skirbekk V, Søreide K, Soshnikov S, Stein DJ, Sykes BL, Tabb KM, Temesgen AM, Tenkorang EY, Theadom AM, Tran BX, Vasankari TJ, Vavilala MS, Vlassov W, Woldeyohannes SM, Yip P, Yonemoto N, Younis MZ, Yu C, Murray CIL, Vos T (2016) The global burden of injury: incidence, mortality, disability-adjusted life years and time trends from the Global Burden of Disease study 2013. Inj Prev 22:3-18

2. van Wessem KJP, Leenen LPH (2017) Reduction in mortality rates of postinjury multiple organ dysfunction syndrome: a shifting paradigm? A prospective population based cohort study. Shock. https://doi.org/10.1097/SHK.0000000000000938

3. Maegele M, Lefering R, Yucel N, Tjardes T, Rixen D, Paffrath T, Simanski C, Neugebauer E, Bouillon B (2007) Early coagulopathy in multiple injury: an analysis from the German Trauma Registry on 8724 patients. Injury 38:298-304. https://doi.org/10.1016/j.injury.2006.10.003

4. Ross SW, Christmas AB, Fischer PE, Holway H, Walters AL, Seymour R, Gibbs MA, Heniford BT, Sing RF (2015) Impact of common crystalloid solutions on resuscitation markers following Class I hemorrhage: a randomized control trial. J Trauma Acute Care Surg 79:732-740

5. Mezidi M, Ould-Chikh M, Deras P, Maury C, Martinez O, Capdevila X, Charbit J (2017) Influence of late fluid management on the outcomes of severe trauma patients: a retrospective analysis of 294 severely-injured patients. Injury 48:19641971. https://doi.org/10.1016/j.injury.2017.06.005

6. Haut ER, Kalish BT, Cotton BA, Efron DT, Haider AH, Stevens KA, Kieninger AN, Cornwell EE, Chang DC (2011) Prehospital intravenous fluid administration is associated with higher mortality in trauma patients: a National Trauma Data Bank analysis. Ann Surg 253:371-377. https://doi.org/10.1097/SLA.0b013e318207c24f

7. Harrois A, Baudry N, Huet O, Kato H, Dupic L, Lohez M, Ziol M, Vicaut E, Duranteau J (2015) Norepinephrine decreases fluid requirements and blood loss while preserving intestinal villi microcirculation during fluid resuscitation of uncontrolled hemorrhagic shock in mice. Anesthesiology 122:1093-1102. https://doi.org/10.1097/ALN. 0000000000000639

8. Hylands M, Godbout M-P, Mayer SK, Fraser WD, Vanasse A, Leclair M-A, Turgeon AF, Lauzier F, Charbonney E, Trottier V, Razek TS, Roy A, D'Aragon F, Belley-Cote E, Day AG, Le Guillan S, Sabbagh R, Lamontagne F (2017) Vasopressor use following traumatic injury - a single center retrospective study. PLoS One 12:e0176587

9. Chesnut RM, Marshall LF, Klauber MR, Blunt BA, Baldwin N, Eisenberg HM, Jane JA, Marmarou A, Foulkes MA (1993) The role of secondary brain injury in determining outcome from severe head injury. J Trauma 34:216-222

10. Hylands M, Toma A, Beaudoin N, Frenette AJ, D'Aragon F, Belley-Cote E, Charbonney E, Moller MH, Laake JH, Vandvik PO, Siemieniuk RA, Rochwerg B, Lauzier F, Green RS, Ball I, Scales D, Murthy S, Kwong JSW, Guyatt G, Rizoli S, Asfar P, Lamontagne F (2017) Early vasopressor use following traumatic injury: a systematic review. BMJ Open 7:e017559. https://doi.org/10.1136/bmjopen-2017-017559

11. Wang P, Hauptman JG, Chaudry $\mathbb{H}$ (1990) Hemorrhage produces depression in microvascular blood flow which persists despite fluid resuscitation. Circ Shock 32:307-318

12. Hierholzer C, Harbrecht B, Menezes JM, Kane J, MacMicking J, Nathan CF, Peitzman AB, Billiar TR, Tweardy DJ (1998) Essential role of induced nitric oxide in the initiation of the inflammatory response after hemorrhagic shock. J Exp Med 187:917-928

13. Thiemermann C, Szabo C, Mitchell JA, Vane JR (1993) Vascular hyporeactivity to vasoconstrictor agents and hemodynamic decompensation in hemorrhagic shock is mediated by nitric oxide. Proc Natl Acad Sci U S A 90:267-271

14. Terada LS, Guidot DM, Leff JA, Willingham IR, Hanley ME, Piermattei D, Repine JE (1992) Hypoxia injures endothelial cells by increasing endogenous xanthine oxidase activity. Proc Natl Acad Sci U S A 89:3362-3366

15. Tan S, Yokoyama Y, Dickens E, Cash TG, Freeman BA, Parks DA (1993) Xanthine oxidase activity in the circulation of rats following hemorrhagic shock. Free Radic Biol Med 15:407-414

16. Poloujadoff M-P, Borron SW, Amathieu R, Favret F, Camara MS, Lapostolle F, Vicaut E, Adnet F (2007) Improved survival after resuscitation with norepinephrine in a murine model of uncontrolled hemorrhagic shock. Anesthesiology 107:591-596 
17. Stadlbauer KH, Wagner-Berger HG, Raedler C, Voelckel WG, Wenzel V, Krismer AC, Klima G, Rheinberger K, Nussbaumer W, Pressmar D, Lindner KH, Konigsrainer A (2003) Vasopressin, but not fluid resuscitation, enhances survival in a liver trauma model with uncontrolled and otherwise lethal hemorrhagic shock in pigs. Anesthesiology 98:699-704. https:// doi.org/10.1097/00000542-200303000-00018

18. Voelckel WG, Raedler C, Wenzel V, Lindner KH, Krismer AC, Schmittinger CA, Herff H, Rheinberger K, Konigsrainer A (2003) Arginine vasopressin, but not epinephrine, improves survival in uncontrolled hemorrhagic shock after liver trauma in pigs. Crit Care Med 31:1160-1165. https://doi.org/10.1097/01.CCM.0000060014.75282.69

19. Prunet B, Prat N, Couret D, Cordier P-Y, De Bourmont S, Lambert D, Asencio Y, Meaudre E, Michelet P (2014) Midterm effects of fluid resuscitation strategies in an experimental model of lung contusion and hemorrhagic shock. Shock 41:159-165

20. Ichimura T, Bonventre JV, Bailly V, Wei H, Hession CA, Cate RL, Sanicola M (1998) Kidney injury molecule-1 (KIM-1), a putative epithelial cell adhesion molecule containing a novel immunoglobulin domain, is up-regulated in renal cells after injury. J Biol Chem 273:4135-4142

21. Wray C, Mao Y, Pan J, Chandrasena A, Piasta F, Frank JA (2009) Claudin-4 augments alveolar epithelial barrier function and is induced in acute lung injury. A J P Lung Cell Mol Physiol 297:L219-L227. https://doi.org/10.1152/ajplung.00043.2009

22. Ito D, Tanaka K, Suzuki S, Dembo T, Fukuuchi Y (2001) Enhanced expression of Iba1, ionized calcium-binding adapter molecule 1, after transient focal cerebral ischemia in rat brain. Stroke 32:1208-1215

23. Fangio P, Asehnoune K, Edouard A, Smail N, Benhamou D (2005) Early embolization and vasopressor administration for management of life-threatening hemorrhage from pelvic fracture. J Trauma 58:978-984 discussion 984

24. Rönn T, Lendemans S, de Groot H, Petrat F (2011) A new model of severe hemorrhagic shock in rats. Comp Med 61:419-426

25. Boucher M, Wann BP, Kaloustian S, Cardinal R, Godbout R, Rousseau G (2006) Reduction of apoptosis in the amygdala by an A2A adenosine receptor agonist following myocardial infarction. Apoptosis 11:1067-1074. https://doi.org/10.1007/ s10495-006-6313-6

26. Krawisz JE, Sharon P, Stenson WF (1984) Quantitative assay for acute intestinal inflammation based on myeloperoxidase activity. Assessment of inflammation in rat and hamster models. Gastroenterology 87:1344-1350

27. Gelman S, Mushlin PS (2004) Catecholamine-induced changes in the splanchnic circulation affecting systemic hemodynamics. Anesthesiology 100:434-439

28. Drees JA, Rothe CF (1974) Reflex venoconstriction and capacity vessel pressure-volume relationships in dogs. Circ Res 34:360-373

29. Nouira S, Elatrous S, Dimassi S, Besbes L, Boukef R, Mohamed B, Abroug F (2005) Effects of norepinephrine on static and dynamic preload indicators in experimental hemorrhagic shock. Crit Care Med 33:2339-2343

30. Maas JJ, Pinsky MR, de Wilde RB, de Jonge E, Jansen JR (2013) Cardiac output response to norepinephrine in postoperative cardiac surgery patients: interpretation with venous return and cardiac function curves. Crit Care Med 41: 143-150. https://doi.org/10.1097/CCM.0b013e318265ea64

31. Persichini R, Silva S, Teboul J-L, Jozwiak M, Chemla D, Richard C, Monnet X (2012) Effects of norepinephrine on mean systemic pressure and venous return in human septic shock. Crit Care Med 40:3146-3153. https://doi.org/10.1097/CCM. 0b013e318260c6c3

32. Dalibon N, Schlumberger S, Saada M, Fischler M, Riou B (1999) Haemodynamic assessment of hypovolaemia under general anaesthesia in pigs submitted to graded haemorrhage and retransfusion. $\mathrm{Br} J$ Anaesth 82:97-103

33. Proctor KG, Duling BR (1982) Oxygen-derived free radicals and local control of striated muscle blood flow. Microvasc Res 24:77-86

34. Dubin A, Pozo MO, Ferrara G, Murias G, Martins E, Canullan C, Canales HS, Kanoore Edul VS, Estenssoro E, Ince C (2009) Systemic and microcirculatory responses to progressive hemorrhage. Intensive Care Med 35:556-564. https://doi.org/10. 1007/s00134-008-1385-0

35. Cronin RE, de Torrente A, Miller PD, Bulger RE, Burke TJ, Schrier RW (1978) Pathogenic mechanisms in early norepinephrine-induced acute renal failure: functional and histological correlates of protection. Kidney Int 14:115-125

36. Chawla LS, Bellomo R, Bihorac A, Goldstein SL, Siew ED, Bagshaw SM, Bittleman D, Cruz D, Endre Z, Fitzgerald RL, Forni L, Kane-Gill SL, Hoste E, Koyner J, Liu KD, Macedo E, Mehta R, Murray P, Nadim M, Ostermann M, Palevsky PM, Pannu N, Rosner M, Wald R, Zarbock A, Ronco C, Kellum JA, 16 OBOTADQIW (2017) Acute kidney disease and renal recovery: consensus report of the Acute Disease Quality Initiative (ADQI) 16 Workgroup. Nat Rev Nephrol 13(4):13-241. https://doi. org/10.1038/nrneph.2017.2

37. Arcaroli J, Yang K-Y, Yum H-K, Kupfner J, Pitts TM, Park JS, Strassheim D, Abraham E (2002) Effects of catecholamines on kinase activation in lung neutrophils after hemorrhage or endotoxemia. J Leukoc Biol 72:571-579

38. Rokkam D, Lafemina MJ, Lee JW, Matthay MA, Frank JA (2011) Claudin-4 levels are associated with intact alveolar fluid clearance in human lungs. Am J Pathol 179:1081-1087. https://doi.org/10.1016/j.ajpath.2011.05.017

39. Mazzon E, Cuzzocrea S (2007) Role of TNF-alpha in lung tight junction alteration in mouse model of acute lung inflammation. Respir Res 8:75. https://doi.org/10.1186/1465-9921-8-75

40. Ayata C, Ropper AH (2002) Ischaemic brain oedema. J Clin Neurosci 9:113-124

41. Warner DS, Boehland LA (1988) Effects of iso-osmolal intravenous fluid therapy on post-ischemic brain water content in the rat. Anesthesiology 68:86-91

42. Kuebler WM, Abels C, Schuerer L, Goetz AE (1996) Measurement of neutrophil content in brain and lung tissue by a modified myeloperoxidase assay. Int J Microcirc Clin Exp 16:89-97

43. Eser O, Kalkan E, Cosar M, Buyukbas S, Avunduk MC, Aslan A, Kocabas V (2007) The effect of aprotinin on brain ischemic-reperfusion injury after hemorrhagic shock in rats: an experimental study. J Trauma 63:373-378

44. Nikolian VC, Dekker SE, Bambakidis T, Higgins GA, Dennahy IS, Georgoff PE, Williams AM, Andjelkovic AV, Alam HB (2018) Improvement of blood-brain barrier integrity in traumatic brain injury and hemorrhagic shock following treatment with valproic acid and fresh frozen plasma. Crit Care Med 46:e59-e66. https://doi.org/10.1097/CCM. 0000000000002800

45. Cavus E, Meybohm P, Doerges V, Hugo H-H, Steinfath M, Nordstroem J, Scholz J, Bein B (2009) Cerebral effects of three resuscitation protocols in uncontrolled haemorrhagic shock: a randomised controlled experimental study. Resuscitation 80:567-572. https://doi.org/10.1016/j.resuscitation.2009.01.013 